\title{
Cryoablation of the accessory pathway in Wolff- Parkinson-White syndrome: initial results and long term follow up
}

\author{
EDWARD ROWLAND, * KILLIAN ROBINSON, STEPHEN EDMONDSON, $\dagger$ \\ DENNIS M KRIKLER, HUGH H BENTALL
}

From the Division of Cardiovascular Disease, Royal Postgraduate Medical School, Hammersmith Hospital, London

SUMMARY Cryoablation of the accessory pathway was used in the management of 20 patients with pre-excitation syndromes. All patients had presented with paroxysmal atrioventricular reentrant tachycardia; in addition, six had experienced atrial fibrillation. In 16 patients pre-excitation was overt and in four the accessory pathway was concealed. Intraoperative epicardial and endocardial mapping showed 10 left free wall pathways, seven septal pathways, and four right free wall pathways. One patient had two right free wall accessory pathways. There was one postoperative death (from a ruptured cerebral haemangioma) and one patient had transient hemiparesis. There was early recurrence of arrhythmia or pre-excitation in six patients and five of these were among the first ten in the series. Four of the six underwent successful reoperation; 17 patients remain symptom free of all antiarrhythmic treatment. Two patients did not undergo reoperation-one became symptom free on drugs that had previously been ineffective and the other received an antitachycardia pacemaker. The mean period of follow up was six years.

Accessory pathway function was not restored and atrioventricular nodal function was preserved in all patients, demonstrating the feasibility of this technique in the long term management of patients with the pre-excitation syndrome.

Since surgical operation in patients with WolffParkinson-White syndrome was first attempted in $1967^{1}$ and described definitively in $1968^{2}$ various techniques of dissection or cryoablation have been used to ablate the accessory pathway. ${ }^{34}$ Ablation by endocardial dissection must be performed under induced cardiac arrest in the open heart. Cryosurgery may obviate the need for extensive endocardial dissection $^{4}$ and may, combined with dissection, be applied to the epicardium without necessarily opening the heart. ${ }^{.6}$

We have used cryosurgery as the primary mode of ablation of accessory atrioventricular pathways since 1977 and report our long term follow up as well as the immediate results.

Requests for reprints to Dr Edward Rowland, Cardiac Department, Brompton Hospital, Fulham Road, London SW3 6HP.

Present addresses: «Cardiothoracic Institute, Fulham Road, London SW3; +St Bartholomew's Hospital, West Smithfield, London EC1.

Accepted for publication 9 November 1987

\section{Patients and methods}

Between 1977 and 1985238 patients undergoing electrophysiological study were shown to have accessory atrioventricular pathways. Of these, 186 were successfully treated medically, 13 had antitachycardia pacemakers implanted, and 19 required no treatment. Twenty patients ( 11 female, 9 male), aged $21-58$ (mean 39) years had an operation (table). All had presented with paroxysmal orthodromic atrioventricular reentrant tachycardia. Six had also experienced paroxysmal atrial fibrillation with anterograde conduction across the accessory pathway and three of them had been resuscitated from ventricular fibrillation. In 16 pre-excitation was overt whereas in four it was concealed. Sustained orthodromic atrioventricular reentry tachycardia was inducible in all patients; one also had antidromic tachycardia. The indications for operation were failure of medical management in 13 patients with paroxysmal reentrant atrioventricular tachycardia, refusal of medical treatment in another, and atrial 
Table Accessory pathway location and outcome in patients undergoing surgical cryoablation

\begin{tabular}{|c|c|c|c|c|c|c|c|}
\hline Patient & Age at operation & Sex & Pathway location & $\begin{array}{l}\text { Arrhythmia } \\
\text { recurrence }\end{array}$ & Reoperation & $\begin{array}{l}\text { Clinical } \\
\text { outcome }\end{array}$ & $\begin{array}{l}\text { Follow up } \\
\text { (years) }\end{array}$ \\
\hline 1 & 27 & $\mathbf{F}$ & Right free wall (2) & - & - & 1 & $10 \cdot 2$ \\
\hline 2 & 46 & $\mathbf{M}$ & Left posteroseptal & - & - & 1 & $10 \cdot 1$ \\
\hline 3 & 21 & $\mathbf{F}$ & Right posteroseptal & + & + & 1 & $9 \cdot 5$ \\
\hline 4 & 36 & $\mathbf{M}$ & Right posteroseptal & - & - & 1 & $9 \cdot 2$ \\
\hline 5 & 47 & $\mathbf{F}$ & Left free wall & - & - & 1 & $8 \cdot 8$ \\
\hline 6 & 40 & $\mathbf{F}$ & Left free wall & + & - & 3 & $8 \cdot 7$ \\
\hline 7 & 58 & $\mathbf{F}$ & Left posteroseptal & + & - & 2 & $8 \cdot 6$ \\
\hline 8 & 48 & $\mathbf{F}$ & Left free wall & + & + & 1 & $8 \cdot 5$ \\
\hline 9 & 49 & $\mathbf{F}$ & Left free wall & - & - & & $\star$ \\
\hline 10 & 40 & $\mathbf{F}$ & Left free wall & + & + & 1 & $6 \cdot 2$ \\
\hline 11 & 49 & $\mathbf{M}$ & Right posteroseptal & - & - & 1 & $6 \cdot 1$ \\
\hline 12 & 36 & $\mathbf{M}$ & Left free wall & - & - & 1 & 5.9 \\
\hline 13 & 41 & $\mathbf{M}$ & Left posteroseptal & - & - & 1 & $4 \cdot 6$ \\
\hline 14 & 41 & $\mathbf{M}$ & Right free wall & - & - & 1 & 3.9 \\
\hline 15 & 30 & $\mathbf{M}$ & Left free wall & - & - & 1 & $2 \cdot 8$ \\
\hline 16 & 33 & $\mathbf{F}$ & Left freewall & + & + & 1 & $2 \cdot 7$ \\
\hline 17 & 42 & $\mathbf{M}$ & Left free wall & - & - & 1 & $2 \cdot 3$ \\
\hline 18 & 21 & $\mathbf{F}$ & Right posteroseptal & - & - & $\overline{1}$ & $1 \cdot 1$ \\
\hline 19 & 38 & $\mathbf{M}$ & Right free wall & - & - & 1 & $1 \cdot 1$ \\
\hline 20 & 29 & $\mathbf{F}$ & Left free wall & - & - & 1 & $1 \cdot 0$ \\
\hline
\end{tabular}

Clinical response: 1, asymptomatic; 2, asymptomatic on previously ineffective medication; 3, no improvement.

^Died suddenly 24 hours after operation from rupture of a cerebral haemangioma.

fibrillation with rapid ventricular response in six. The 13 patients with atrioventricular tachycardia had received atrioventricular nodal blocking drugs as well as class I agents; the six patients with atrial fibrillation had also received class I agents and five had been given amiodarone, without success.

\section{ELECTROPHYSIOLOGICAL STUDY}

Electrophysiological study was carried out before and after surgery in all patients. ${ }^{7}$ Intraoperative electrophysiological mapping was carried out with atrial and ventricular reference electrodes and $a$ hand held exploring electrode. ${ }^{8}$ Detailed and precise atrial and ventricular mapping was performed to determine the pathway location. ${ }^{5}$ Electrophysiological study was repeated 6-10 days after operation.

\section{SURGICAL TECHNIQUE}

Cardiopulmonary bypass was started in the standard manner. All applications of the cryoprobe were made during continuous coronary perfusion without aortic cross clamping. Transient suppression of preexcitation during temporary cryothermia was used to confirm the pathway location ${ }^{4}$ (figs 1 and 2). Cryoablation was first performed epicardially at the site of earliest atrial and/or ventricular activation in the atrioventricular groove $e^{4}$ for a maximum of five minutes. If this epicardial approach was unsuccessful the accessory pathway was located by endocardial mapping and the cryoprobe was applied. Right sided pathways were approached by a right atriotomy and those on the left side by opening the atrial septum through a right atriotomy. During this procedure temporary ventricular fibrillation was induced to prevent air embolism; when the mitral valve was made regurgitant and an aortic vent incision made the heart was defibrillated and endocardial mapping and ablation performed. A similar procedure, in reverse order, was undertaken during closure of the heart.

In patients 1-8 single discrete cryolesions were used until accessory pathway conduction was abolished. From patient 9 onwards at least three contiguous lesions were made even if accessory pathway conduction was abolished by the first.

Septal cryolesions were delivered while atrioventricular conduction was monitored, and cooling was stopped immediately atrioventricular block occurred.

\section{Results}

\section{ELECTROPHYSIOLOGICAL MAPPING}

Intraoperative mapping confirmed the presence of an accessory atrioventricular connection in each patient and in one patient two right free wall pathways were found.

\section{SURGICAL RESULTS}

Two of the 10 left free wall pathways were ablated epicardially; one required additional dissection through the epicardial fat pad in the atrioventricular groove. In seven of the remaining eight, accessory pathway conduction was abolished by endocardial cryoablation. In the eighth, permanent interruption of the accessory pathway could not be achieved at the 

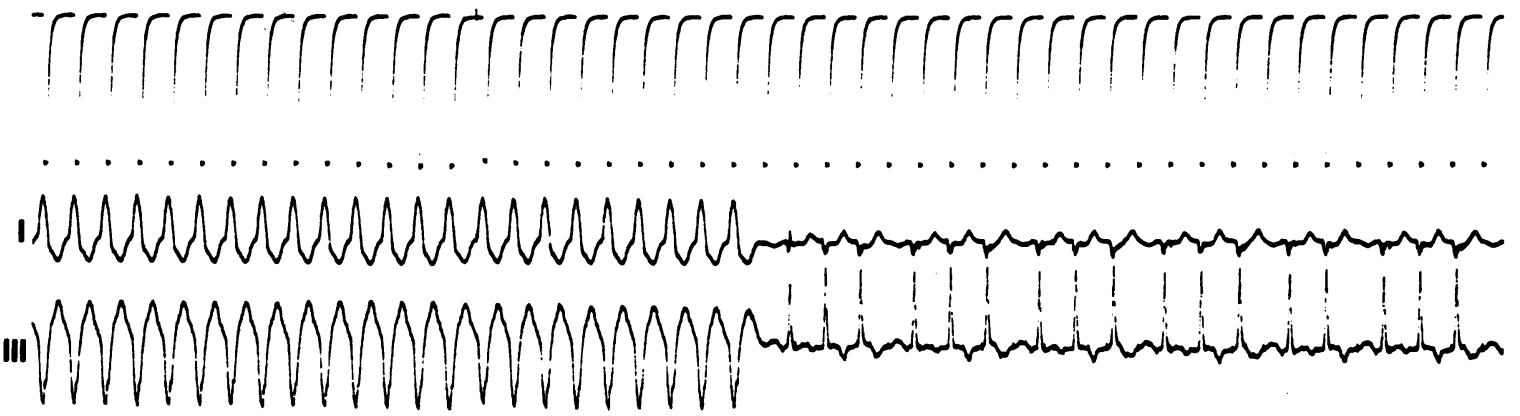

Fig 1 During continuous atrial pacing (top) application of the cryoprobe to the site of the accessory pathway resulted in the disappearance of pre-excitation and conduction from atria to ventricles occurred across the atrioventricular node, with type 1 second degree block.
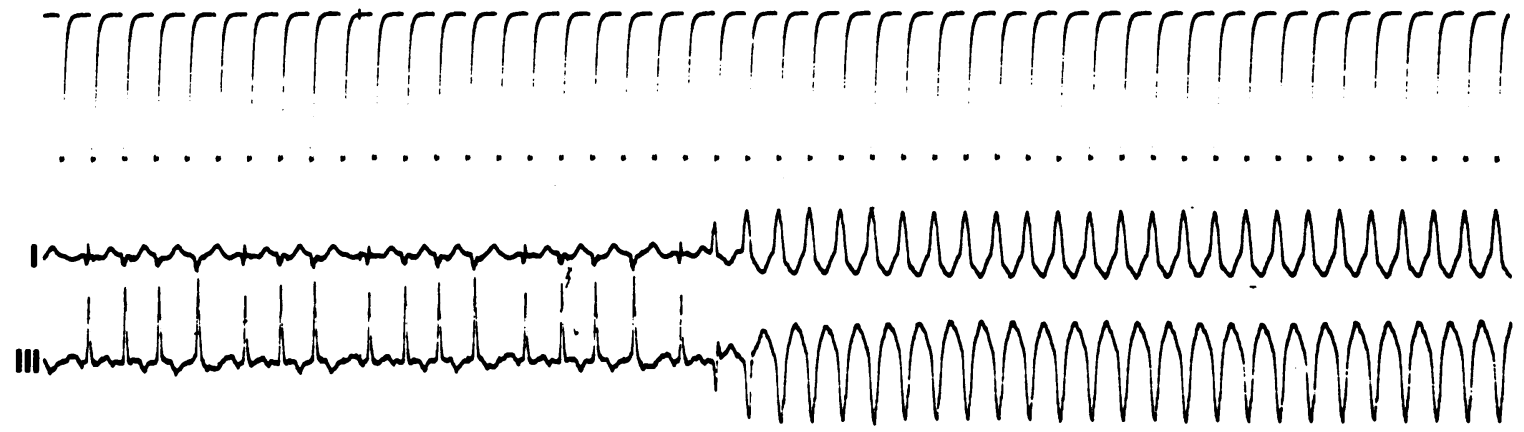

Fig 2 Removal of the cryoprobe and rewarming of the site of pre-excitation was followed by restoration of $1: 1$ atrioventricular conduction across the accessory pathway.

first operation despite both epicardial and endocardial freezing. At reoperation epicardial dissection and cryoablation did not succeed but repeat endocardial freezing was effective. Of the four right free wall pathways, one was successfully ablated by the epicardial approach and the remainder were ablated endocardially. All seven posteroseptal pathways required endocardial cryoablation. In those with right free wall and posteroseptal accessory pathways, pre-excitation was absent at the end of the operation.

\section{POSTOPERATIVE ACCESSORY PATHWAY \\ FUNCTION}

In five patients accessory pathway conduction was present either at the end of the operation (two cases) or recurred within 24 hours. Of the five, arrhythmia recurred early in three and prompt reoperation was successful in all. In the fourth, accessory pathway behaviour was unchanged after the operation although spontaneous arrhythmia did not recur until three months later; reoperation then was successful. In the fifth, electrophysiological testing showed impaired anterograde accessory pathway conduction and reoperation was not performed. Reentrant tachycardia recurred after three months and has been controlled successfully with an implanted antitachycardia pacemaker.

\section{POSTOPERATIVE COMPLICATIONS}

One patient died 24 hours after operation. A ruptured cerebral haemangioma was found at necropsy. In another patient there was transient hemiparesis. In a third who had a septal accessory pathway there was transient complete atrioventricular nodal block which resolved within 10 days and has not recurred.

Long term follow up has ranged from 1 to 10 years (mean 6). Tachycardia recurred in a further patient after three months: postoperative electrophysiological study had shown normal anterograde conduction and apparent abolition of the concealed accessory atrioventricular pathway. This patient remains free of arrhythmias on medications that had previously been unsuccessful.

\section{Discussion}

In the Wolff-Parkinson-White syndrome, arrhythmia may be troublesome and is sometimes life threatening. ${ }^{9}$ Not all patients respond to medications 
and their long term use, even when successful, may be associated with adverse effects. More specifically, in patients with this syndrome a short anterograde effective refractory period of the accessory pathway is associated with a rapid ventricular response to atrial fibrillation which may induce ventricular fibrillation. ${ }^{10}$

Surgical operation may offer definitive cure of the pre-excitation syndrome, abolish the incidence of atrial fibrillation, ${ }^{11}$ and obviate the need for medication. The first definitive surgical interruption of an accessory pathway used atrioventricular disconnection. ${ }^{2}$ This was superseded by the use of cryosurgery $^{4}$ which has undergone considerable modification. ${ }^{56}$ Other techniques, notably endocardial dissection with or without cryoablation, are also successful ${ }^{312}$ and surgical operation is now used extensively. ${ }^{13} 14$ The well substantiated success rate of the endocardial approach will also determine the method chosen by individual institutions. ${ }^{3}$

Advantages of the cryosurgical technique include the production of a well demarcated area of damage $e^{15}$ and the ahility to interrupt conduction transiently before permanent ablation is performed (figs 1 and 2). Although an open heart procedure with cardiopulmonary bypass may sometimes be avoided ${ }^{16}$ this will not be possible if other procedures, such as valve surgery, are required at the same time.

Septal accessory pathways may present difficulties because of the proximity of the specialised conduction system and, in the case of cryosurgery, the increased thickness of the atrioventricular tissue in this region. In this series, however, cryosurgery, in some cases from both sides of the septum, effectively ablated all seven septal pathways.

In a recent study which included a general review, delta waves recurred in approximately $12 \%$ of 388 patients, many of whom had required reoperation. ${ }^{13}$ Antiarrhythmic treatment which had been unsuccessful before operation was often successful thereafter. In six of our patients pre-excitation recurred. In five this was early, within 24 hours of operation; in four reoperation was carried out and was successful. In the fifth patient the presence of excessive adipose tissue on the epicardial and endocardial aspects of the atrioventricular groove made accurate localisation uncertain and effective cryoablation impossible. Limited endocardial dissection was also unsuccessful and reoperation was not advised. The sixth patient had recurrence of arrhythmia after three months despite apparently successful pathway ablation as judged at electrophysiological reinvestigation 10 days after the operation.

This relatively high frequency of recurrence probably reflects early experience with this technique. Intraoperative mapping showed the pattern of pre-excitation and its participation in arrhythmia to be the same as that during the first operation, suggesting temporary damage to the accessory pathway rather than the presence of widely separated multiple bypass tracts. ${ }^{17}$ After the recurrence of arrhythmia in patient 8 , in whom a single cryolesion was used at the first operation, at least three adjacent cryolesions were used.

The length of follow up after surgery in these patients confirms the usefulness of this technique in the long term management of the pre-excitation syndrome. Most patients are well, require no treatment, and lead normal lives. Technical improvements have led to better immediate results in the later patients, but should pre-excitation recur early it can be controlled by reoperation with good expectation of the maintenance of normal atrioventricular conduction and abolition of the presenting arrhythmia.

\section{References}

1 Burchell HB, Frye RL, Anderson MW, McGoon DC. Atrioventricular and ventriculoatrial excitation in Wolff-Parkinson-White syndrome (type B). Temporary ablation at surgery. Circulation 1967; 36:663-72.

2 Cobb FR, Blumenschein SD, Sealy WC, Boineau JP, Wagner GS, Wallace AG. Successful surgical interruption of the bundle of Kent in a patient with Wolff-Parkinson-White syndrome. Circulation 1968;38:1018-29.

3 Cox J, Gallagher JJ, Cain ME. Surgical interruption of accessory bypass tracts. $J$ Thorac Cardiovasc Surg 1985;90:490-501.

4 Gallagher JJ, Sealy WC, Anderson RW, et al. Cryosurgical ablation of accessory atrioventricular connections. A method for correction of the pre-excitation syndrome. Circulation 1977;55:471-9.

5 Guiraudon GM, Klein GJ, Jones D, Kerr CR. Surgical treatment of Wolff-Parkinson-White syndrome. Can J Surg 1983;26:147-9.

6 Guiraudon GM, Klein GJ, Sharma AD, Jones DL, McLellan DG. Surgical ablation of posterior septal accessory pathways in the Wolff-Parkinson-White syndrome by a closed heart technique. $J$ Thorac Cardiovasc Surg 1986;92:406-13.

7 Curry PVL. Fundamentals of arrhythmias: modern methods of investigation. In: Krikler DM, Goodwin JF, eds. Cardiac arrhythmias. The modern electrophysiological approach. London: WB Saunders, 1975:39-80.

8 Gallagher JJ, Kasell J, Sealy WC, Pritchett ELC, Wallace AG. Epicardial mapping in the WolffParkinson-White syndrome. Circulation 1978;57: 854-66.

9 Dreifus LS, Haiat R, Watanabe Y, Arriaga J, Reitman $N$. Ventricular fibrillation: a possible mechanism of sudden death in patients with Wolff-ParkinsonWhite syndrome. Circulation 1971;43:520-7. 
10 Klein GJ, Bashore TM, Sellers TD, Pritchett ELC, Smith WM, Gallagher JJ. Ventricular fibrillation in the Wolff-Parkinson-White syndrome. $N$ Engl J Med 1979;301:1080-5.

11 Sharma AD, Klein GJ, Guiraudon M, Milstein S. Atrial fibrillation in the Wolff-Parkinson-White syndrome: incidence after surgical ablation of the accessory pathway. Circulation 1985;72:161-9.

12 Iwa T, Mitsui T, Misaki T, Mukai K, Magara T, Kamata E. Radical surgery cure of Wolff-ParkinsonWhite syndrome: the Kanazawa experience. $J$ Thorac Cardiovasc Surg 1986;91:225-33.

13 Fischell TA, Stinson EB, Derby GC, Swerdlow CD. Long-term follow-up after surgical correction of Wolff-Parkinson-White syndrome. J Am Coll Cardiol 1987;9:283-7.
14 Holmes DR, Osborn MJ, Gersh B, Maloney JD, Danielson GK. The Wolff-Parkinson-White syndrome: a surgical approach. Mayo Clin Proc 1982;57:345-50.

15 Misaki T, Allwork SP, Bentall HH. Longterm effects of cryosurgery in the sheep heart. Cardiovasc Res 1983;17:61-9.

16 Klein GJ, Guiraudon GM, Garth-Perkins D, Jones DL, Yee R, Jarvis E. Surgical correction of the WolffParkinson-White syndrome in the closed heart using cryosurgery: a simplified approach. J Am Coll Cardiol 1984;3:405-9.

17 Spurrell RAJ, Krikler DM, Sowton E. Problems concerning assessment of anatomical site of accessory pathway in Wolff-Parkinson-White syndrome. Br Heart J 1975;37:127-35. 